\title{
Siderophoregenic Acinetobacter calcoaceticus isolated from wheat rhizosphere with strong PGPR activity
}

\author{
Sarode Prashant $D^{1}$, Rane Makarand $R^{2}$, Chaudhari Bhushan $\mathrm{L}^{3}$ and Chincholkar Sudhir $\mathrm{B}^{3 *}$ \\ ${ }^{1}$ Department of Microbiology, D. N. College, Faizpur, Jalgaon, Maharashtra, India; ${ }^{2}$ Biosynthetics, 53, Visanji \\ Nagar, Jalgaon 425001, Maharashtra, India; ${ }^{3}$ School of Life Sciences, North Maharashtra University, P B 80, \\ Jalgaon 425001, Maharashtra, India \\ E-mail:chincholkarsb@hotmail.com
}

Received 26 September 2008; received in revised form 8 November 2008; accepted 8 November 2008

\begin{abstract}
Thirty-two bacterial isolates were obtained from wheat rhizosphere in black cotton soils of North Maharashtra region and subsequently tested for in-vitro siderophore production. Wheat isolate SCW1, being a strong siderophore producer, was selected, identified and confirmed as Acinetobacter calcoaceticus. The strain produced catechol type of siderophores during exponential phase which was influenced by iron content of medium. Seed bacterization with siderophoregenic $A$. calcoaceticus improved plant growth in pot and field studies. Such PGPR activity was attributed to the ability of strain to solubilise phosphates and produce IAA. Siderophore mediated antagonism was observed against common phytopathogens viz., Aspergillus flavus, A. niger, Colletotrichum capsicum and Fusarium oxysporum.
\end{abstract}

Keywords: Acinetobacter, Siderophore, PGPR, wheat growth, phytopathogens

\section{INTRODUCTION}

Siderophores are low molecular weight bio-molecules secreted by micro-organisms in response to iron starvation for acquisition of iron from insoluble forms by mineralization and sequestration (Lankford, 1973). Although some siderophores are known to chelate other ions, their specificity and avidity for iron is the most consistent feature (Chincholkar et al., 2007a). Lost ability to synthesize siderophores lead to loss of ability to synthesize cyanide and thus marred biocontrol abilities of strain proves physiological importance of iron (Voisard et al., 1989). Siderophores produced by rhizosphere inhabitants has been studied well and it has been reported that ability to produce siderophores not only improve rhizosphere colonization of producer strain but also play an important role in iron nutrition of plant (Vansuyt et al., 2007) and antagonism against phytopathogens (Chincholkar et al., 2007b). Role of siderophores in induced systemic resistance (ISR) in plants was also well appreciated (De Meyer et al., 1999).

Such unequivocal importance of iron in plant growthpromotion and biological control encouraged us to screen new plant growth promoting rhizobacteria (PGPR) on the basis of its ability to produce siderophores to quench iron. Black cotton soil of North Maharashtra region is unique and known as elite soil for crops like cotton, wheat and banana. Long-standing cash crop like banana with its long big leaves and stem avoids exposure of sunlight to soil and maintains high moisture making the soil conductive for growth of microflora. Rotation of crops viz. cotton gram, wheat and groundnut enrich and subsequently cherish the biological nature of the soil which forms an unexplored treasure.

This research has brought a strain in focus which is siderophoregenic and highly efficient plant growth promoter. Although identified as Acinetobacter calcoaceticus, which is a known opportunistic human pathogen and there is apprehension to use opportunistic human pathogens of non clinical origin lacking major pathological features like DNase and hemolytic activity as biocontrol agents; recent literature indicated that it could be reliable and relevant (Bevivino et al., 1994; Hebbar et al., 1999)

\section{MATERIALS AND METHODS}

\section{Materials}

All media components were purchased from Hi-Media Laboratories Pvt. Ltd (India), unless otherwise specified in the text. Throughout the experimentation, analytical/ guaranteed reagent $(A R / G R)$ grade chemicals from $S$. D. Fine chemicals. Pvt. Ltd (India) and ultra-pure water (Millipore, USA) were used. Glassware was cleaned with $6 \mathrm{~N} \mathrm{HCl}$ to remove residual iron and rinsed with pure water followed by drying. All growth media and reagents were handled carefully to avoid iron contamination.

\section{Culture maintenance}

Phytopathogens viz. Aspergillus flavus, $A$. niger, Colletotrichum capsicum and $F$. oxysporum were maintained on potato-dextrose agar (PDA) and the same 
medium was also used for checking antifungal activities of Acinetobacter calcoaceticus. Bacterial isolates obtained during this study were routinely cultivated on nutrient agar and preserved in $30 \%(\mathrm{v} / \mathrm{v})$ glycerol at $-86^{\circ} \mathrm{C}$ for longterm.

\section{Isolation from Rhizosphere}

The sampling sites were located in Jalgaon district of North Maharashtra (Location, 21.05N; 75.40E; soil, black cotton type; annual rainfall, $700 \mathrm{~mm}$; annual temperature, above $27.5^{\circ} \mathrm{C}$; commercial crops, banana, wheat, cotton and sugarcane). Healthy looking wheat plants in the vicinity of diseased plant were selected for sampling. After removal of plant from soil, root portion was cut and packed in sterile plastic bags. These bags were transported to laboratory under cold conditions for immediate processing. Adhering soil was carefully brushed off and plant roots were washed with sterile buffered saline ten times. These roots were then vigorously shaken with new batch of sterile buffered saline for $5-10 \mathrm{~min}$. After serial dilution, $100 \mu \mathrm{L}$ aliquots of desired dilution $\left(10^{-4}-10^{-6}\right)$ were then platted in triplicate on nutrient agar. Plates were incubated at $28^{\circ} \mathrm{C}$ for three days. Well-isolated colonies were selected, purified and maintained as specified above.

\section{Screening for siderophore production}

For inoculum development, a loopful culture of each isolate from nutrient agar slant was separately inoculated in $100 \mathrm{ml}$ of low strength nutrient medium and incubated for $18 \mathrm{~h}$ at $28{ }^{\circ} \mathrm{C}$ on rotary shaker at $120 \mathrm{rpm}$. These grown cultures were inoculated ( $1 \% \mathrm{v} / \mathrm{v}$ inoculum) in sterile succinate medium (Meyer and Abdallah, 1978) separately and incubated on rotary shaker at $28^{\circ} \mathrm{C}, 120$ rpm. Supernatants of $36 \mathrm{~h}$ old cultures were tested for siderophore production by using Universal Chemical Assay comprising Chrom Azurol S (CAS) reagent as described by Schwyn and Neilands (1987). All positive cultures were compared for siderophore production ability as described by Payne (1994) where percent decolorization was calculated by using the following formula.

$$
\text { Percent decolorization }=\frac{A r-A s}{A r} \quad X 100
$$

Where,

$\mathrm{Ar}=$ Absorbance of reference

As $=$ Absorbance of sample at $630 \mathrm{~nm}$.

\section{Identification of selected strain}

Selected strain was subjected to identification as per Bergey's Manual of Systematic Bacteriology (Juni, 1984) and 16S rDNA gene sequencing with eubacteria specific primer set 16F27N (5'-CCAGAGTTTGATCMTGGCTCAG3') and 16R1525XP (5'-TTCTGCAGTC TAGAAGGAGGTGWTCCAGGC-3') (Pidiyar et al., 2004). In order to check the sensitivity of the isolate towards different antibiotics, disc diffusion was done where culture was grown on Muller Hinton Agar in presence of antibiotic impregnated sterile filter paper discs dispensable with octa-disc dispenser (Hi-Media, Mumbai). After $48 \mathrm{~h}$ incubation of plate at $28^{\circ} \mathrm{C}$, either development of zone of inhibition was observed and interpreted as sensitive (S) or resistant $(R)$.

\section{Sideroanalysis}

The presence of hydroxamate and catecholate type of iron chelating functional groups on siderophore molecules present in culture supernatant were detected by performing Csaky test (Csaky, 1948) and Arnow test (Arnow, 1937) respectively. Siderophore production by $A$. calcoaceticus as a function of time was studied by growing it in synthetic succinate medium at $28^{\circ} \mathrm{C}$ and shaken at $120 \mathrm{rpm}$. Growth was monitored optically at 610 $\mathrm{nm}$ and siderophore production at $510 \mathrm{~nm}$ (Arnow, 1937) at an interval of $6 \mathrm{~h}$ up to $60 \mathrm{~h}$. To get more siderophores, culture was grown in $12 \mathrm{~L}$ reactor (Navin Process systems, Pune) with $7 \mathrm{~L}$ succinate medium and incubated for $36 \mathrm{~h}$ with air $0.75 \mathrm{VVM}$, agitation $100 \mathrm{rpm}$ at $28^{\circ} \mathrm{C}$. Biomass was separately harvested by centrifugation at $10,000 \mathrm{rpm}$ for $10 \mathrm{~min}$ at $4{ }^{\circ} \mathrm{C}$. Siderophores in this cell-free supernatant were concentrated on HP-20 (Mitsubishi chemical corporation, Japan) column with a small modification of method described by Budzikiewicz (1993). Briefly, cell free supernatant was acidified to $\mathrm{pH}-6$ with 12 $\mathrm{M} \mathrm{HCl}$ and passed through $\mathrm{HP}-20$ column at the rate 1-2 bed volumes per hour $(40 \times 2.5 \mathrm{~cm})$. This was followed by washing consecutively with water, $50 \%$ methanol, $75 \%$ methanol (@ 4-8 bed volumes per hour). For recovery of siderophores, column was eluted with 100\% methanol (@ 1 bed volume per hour). Methanolic elute was concentrated on rotary evaporator at reduced pressure to obtain yellow-brown colored powder. Spectrum of solution of purified product in methanol was determined on UVvisible spectrophotometer (Nano-drop Technologies, USA). Moreover, pure product was subjected to Fourier Transform Infrared Spectroscopy (Test scan, Shimadzu FTIR 8000 series) in potassium bromide recording from 4000 to 500 per $\mathrm{cm}$.

\section{Phytopathogen inhibition}

Phytopathogen inhibition by $A$. calcoaceticus was studied. A $100 \mu \mathrm{L}$ of siderophore rich bioinoculants was spread on Czapek Dox agar medium amended with/without $50 \mu \mathrm{M}$ of $\mathrm{FeCl}_{3}$ separately. A $7 \mathrm{~mm}$ diameter mycelial disk taken from actively growing phyto-pathogens (grown on Czapek Dox agar) was placed at the centre. In the control supernatant sample was replaced by equal volume of sterile water. Plates were incubated at $28^{\circ} \mathrm{C}$ and mycelial diameter was measured for 5 days. Pure siderophore of $A$. calcoaceticus in the range of $50-500 \mu \mathrm{L} / \mathrm{mL}$ was added in C-Dox agar medium separately and tested against phytopathogen. 


\section{Evaluation of PGPR activity of $\boldsymbol{A}$. calcoaceticus}

PGPR activity was evaluated in triplicate using wheat seeds (variety Lokvan). Seeds were surface sterilized with $0.1 \% \mathrm{HgCl}_{2}$ solution and washed three times with sterile distilled water, subsequently soaked for $1 \mathrm{~h}$ in siderophore rich bio-inoculants $\left(10^{8}\right.$ cfu per $\mathrm{mL}$ ) containing $0.5 \% \mathrm{CMC}$. Aseptic conditions were maintained throughout the process. After drying on surface sterilized polyethylene sheet under clean air, bacterized seeds were sown (8 seeds/pot) in pots containing black cotton soil ( $\mathrm{pH} 7.3)$. Untreated seeds served as control. Pots were watered after every $48 \mathrm{~h}$. Observations like rate of germination, root and shoot length, dry weight of roots and shoots were recorded after 28 days of sowing.

Large-scale field trial was carried out at Vadgaon, Dist Jalgaon in winter (November-February, 2005-2006) with different treatments of PGPR strains viz. $A$. calcoaceticus SCW1, Pseudomonas putida DFC31, $P$. aeruginosa ID 4365 (PAID), and P-suraksha (Pseudomonas sp.), Azotobacter sp. and PSB (Phosphate solublizing bacteria) a commercial formulation of International Panacea, Delhi were used to observe the influence on growth of wheat (variety: Lokvan Mahyco). Bacterized seeds as mentioned above were used for field trials on 5 acres of land. Data on shoot height, root length, chlorophyll in leaves after 50 days, grain yield after 120 days were recorded.

\section{Detection of IAA synthesis and phosphate solubilization}

Indole acetic acid (IAA) production was detected by a method described by Sharaf and Farrag (2004). Briefly, bacterial strain was grown for seven days in tryptophan $(500 \mu \mathrm{g} / \mathrm{mL})$ supplemented nutrient medium at $28^{\circ} \mathrm{C}$. A 2$\mathrm{mL}$ aliquot of the supernatant was acidified with 2 drops of ortho-phosphoric acid and mixed with $4 \mathrm{~mL}$ of Salkowski's reagent $\left(50 \mathrm{~mL}, 35 \%\right.$ perchloric acid $\left.+1 \mathrm{~mL} 0.5 \% \mathrm{FeCl}_{3}\right)$ and allowed to stand at room temperature for $20 \mathrm{~min}$ for development of pink color. Phosphate solubilization by $A$. calcoaceticus was studied by growing the organism on Pikovskaya's agar (1948). After $72 \mathrm{~h}$ plate was observed for zone of clearance around bacterial growth.

\section{RESULTS AND DISCUSSION}

PGPRs are commonly used as inoculants for improving the growth and yield of agricultural crops, however screening for the selection of effective PGPR strains needs to be very critical. This study focuses on the screening for an effective PGPR strain(s) on the basis of their potential to produce siderophore in-vitro because of crucial role of iron in plant nutrition and plant growth promoting activity at large. Siderophoregenic strains have ability to mediate plant growth promotion directly as well as indirectly. Iron-siderophore complex is accepted by plants to quench iron thirst in soil, a direct mechanism, (Sharma and Johri, 2003; Vansuyt et al., 2007) moreover chelation of soluble iron by microbial siderophores leads to growth inhibition of phytopathogen (Bano and Musarrat, 2003).

While performing isolation, only healthy plants in the vicinity of stunted plants were selected. During isolation of bacteria from these plants, loosely associated microflora was discarded as best PGPR strains are known to colonize root surface more intimately as shown by Glandorf et al. (1994). Moreover, fields having record of consistent high yield of cash crops were selected where probability of isolating better PGPR was high. Altogether thirty-two isolates were obtained from different rhizospheres. All isolates were screened for siderophore production as per Universal Chemical Assay given by Schwyn and Neilands (1987) and with its extrapolation, its comparison was done according to method given by Payne (1994). Out of thirty two strains, eight strains were able to grow in iron deficient synthetic medium and produced siderophores among which SCW1 showed maximum decolorization of CAS reagent (Figure 1). Instant conversion from blue to golden yellow color after reaction of cell free extract with CAS reagent confirmed production of siderophores with $58 \%$ de-colorization as compared to reference containing an equal amount of uninoculated SM. After thrice repetition of this experiment with same outcome, strain SCW1 was selected for further studies. This strain, forming smooth, pale yellow colony on nutrient agar, was identified as Acinetobacter calcoaceticus as per Bergey's Manual of Systematic Bacteriology (Table 1) and the identity was confirmed by 16S rDNA gene sequencing method.

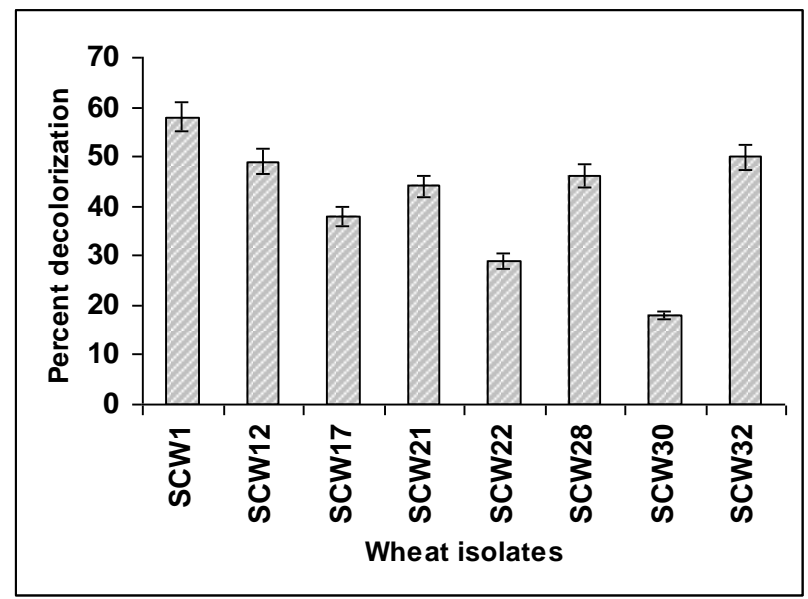

Figure 1: Percent de-colorization of CAS reagent by siderophore containing cell-free supernatant of various wheat isolates

Antibiotic sensitivity/resistance assay of isolate revealed that this strain is sensitive to amikacin, ampicillin, chloramphenicol, ciprofloxacin, colistin, gentamicin, netillin, norfloxacin, tobramycin, piperacillin, where as resistant to carbenicillin, ceftazidime and cephoxitin. Higher sensitivity of strain to clinical antibiotics is consistent with the fact that this is a rhizosphere isolate unlike multi-drug resistant 
clinical isolates described in literature. Culture supernatant of $A$. calcoaceticus showed that Arnow's test gave a strong positive reaction, indicating the presence of the catecholate group on siderophores. However in Csaky's test the intensity of reaction was weak, indicating the presence of hydroxamate group on siderophores in the supernatant.

Table1: Biochemical properties of SCW1 (wheat isolate)

\begin{tabular}{|c|c|}
\hline Biochemical test & Result \\
\hline \multirow{3}{*}{$\begin{array}{l}\text { Gram Character } \\
\text { Shape } \\
\text { Motility }\end{array}$} & Gram negative \\
\hline & Short rods \\
\hline & Non-motile \\
\hline \multicolumn{2}{|l|}{ Enzyme production } \\
\hline Catalase & Positive \\
\hline Urease & Negative \\
\hline \multicolumn{2}{|l|}{ Oxidase } \\
\hline \multicolumn{2}{|l|}{ Gelatinase } \\
\hline \multicolumn{2}{|l|}{ Pigment production } \\
\hline $\begin{array}{l}\text { King's B medium } \\
\text { King 's A medium }\end{array}$ & No pigmentation \\
\hline Nitrate reduction & Negative \\
\hline \multicolumn{2}{|l|}{$\underline{\mathrm{H}}_{2} \underline{\mathrm{S} \text { production }}$} \\
\hline $\begin{array}{l}\text { Blood hemolysis } \\
\text { DNase }\end{array}$ & Negative \\
\hline \multicolumn{2}{|l|}{ Carbon source utilization } \\
\hline \multicolumn{2}{|l|}{ Glucose } \\
\hline \multicolumn{2}{|l|}{ Ribose } \\
\hline \multicolumn{2}{|l|}{ Xylose } \\
\hline \multicolumn{2}{|l|}{ Arabinose } \\
\hline Citrate & Positive \\
\hline \multicolumn{2}{|l|}{ Succinate } \\
\hline \multicolumn{2}{|l|}{ Fumarate } \\
\hline \multicolumn{2}{|l|}{ Pyroglutamate } \\
\hline \multicolumn{2}{|l|}{ Lactate } \\
\hline \multicolumn{2}{|l|}{ Adonitol } \\
\hline Lactose & Neaative \\
\hline Sorbitol & \\
\hline Other PGPR Properties & Positive \\
\hline
\end{tabular}

Initiation of siderophore production in first quarter of exponential growth phase was indicated by the time function of siderophore production in succinate as well as lactate medium. Synthesis continues till the end of stationary phase and its catabolism initiates with initiation of death phase (Figure 2). A. calcoaceticus produced optimum siderophore at $36 \mathrm{~h}$ of incubation period.

Growth of cells was observed maximum at $24 \mathrm{~h}$ and $36 \mathrm{~h}$ in lactate and succinate medium respectively. However, growth and siderophore production occurred earlier in lactate medium indicating low generation time in lactate containing medium. Siderophore production was found to be inversely proportional to iron concentration (Figure 3) whereas growth was directly proportional to iron concentration. Biosynthesis of siderophores in this strain is suppressed completely at $40 \mu \mathrm{M}$ although major suppression occurred at $20 \mu \mathrm{M}$ which emphasized the need of iron and its availability to cells.
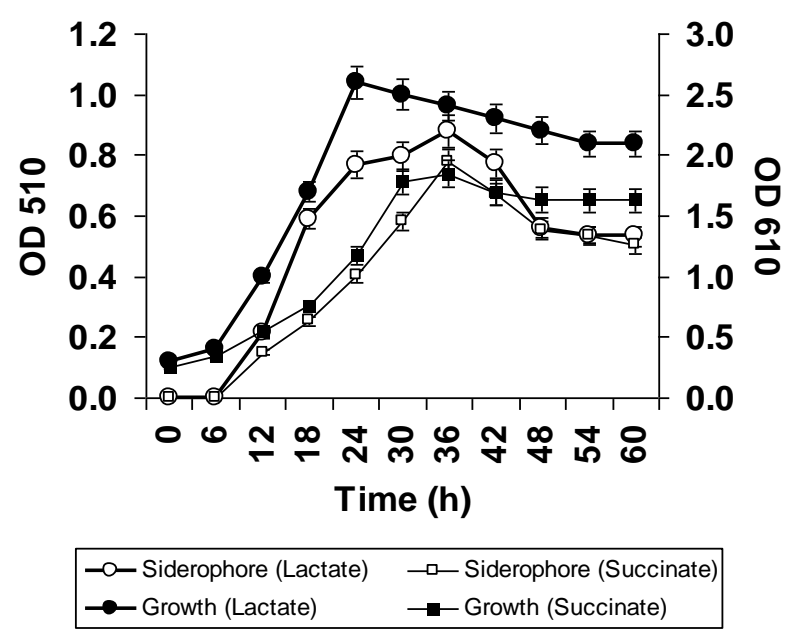

Figure 2: Comparison of $A$. calcoaceticus cell growth (610 $\mathrm{nm})$ and siderophore synthesis $(510 \mathrm{~nm})$ in succinate and lactate containing medium as function of time

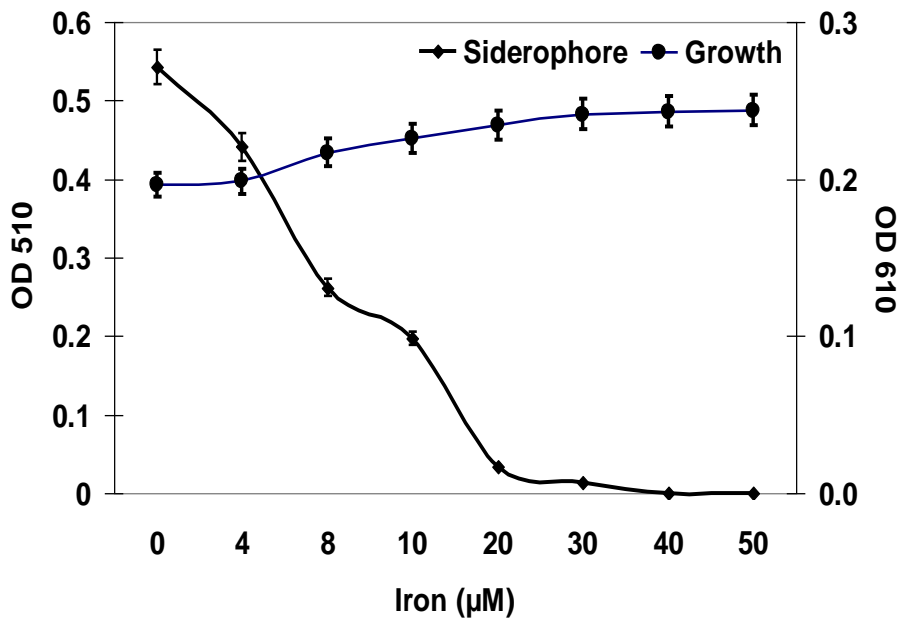

Figure 3: Influence of iron concentration on $A$. calcoaceticus cell growth $(610 \mathrm{~nm})$ and siderophore production $(510 \mathrm{~nm})$

As described under materials and methods, catechol type of siderophore was isolated from supernatant of $A$. calcoaceticus and purified (60 mg/L) by using HP-20. Purified siderophore of $A$. calcoaceticus showed positive CAS test, Csaky's and Arnow's test confirming that it contains both of hydroxamate and catechol group. 
In UV- visible spectrum, two peaks were observed; major peak at $250 \mathrm{~nm}$ while the minor peak at $317 \mathrm{~nm}$ (Figure 4) for sample in methanol which showed an absorption spectrum typical of catecholate compounds. These observations are in agreement with literature (Yamamoto et al., 1994).

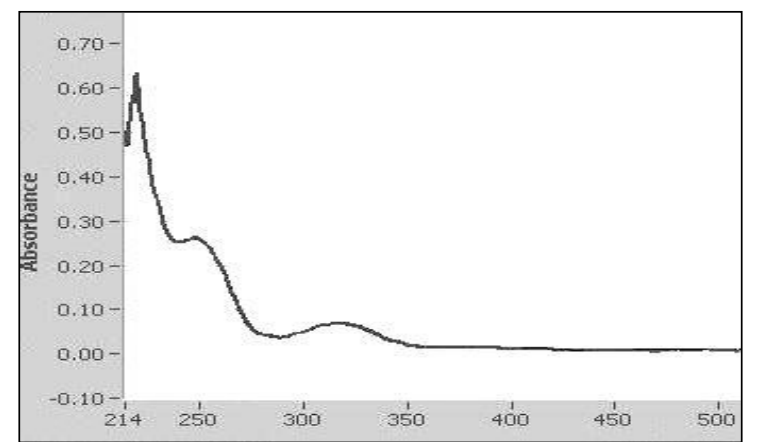

Figure 4: UV-Visible spectra of purified siderophore of $A$ calcoaceticus showing broad peak at $317 \mathrm{~nm}$ and narrow peak at $250 \mathrm{~nm}$

Table 2: Bioassay of Acinetobacter sp. against various phytopathogens

\begin{tabular}{lcc}
\hline \multirow{2}{*}{ Phytopathogen } & \multicolumn{2}{c}{ Inhibition (\%) } \\
\cline { 2 - 3 } & $\begin{array}{l}\text { Absence of } \\
\text { iron }\end{array}$ & $\begin{array}{l}\text { Presence of } \\
\text { iron }\end{array}$ \\
\hline Aspergillus niger & 42.00 & 24.00 \\
A. flavus & 28.57 & 14.29 \\
Fusarium oxysporum & 24.42 & 06.98 \\
Colletotrichum capsicum & 35.29 & 17.65 \\
\hline
\end{tabular}

Values are averages from triplicates

Table 4: Field trial on Lokvan Mahyco of wheat

\begin{tabular}{|c|c|c|c|c|c|}
\hline \multirow[t]{2}{*}{ Treatment } & \multicolumn{3}{|c|}{50 days of growth } & \multicolumn{2}{|l|}{ At harvest } \\
\hline & $\begin{array}{l}\text { Shoot Length } \\
(\mathrm{cm})\end{array}$ & $\begin{array}{l}\text { Root Length } \\
\text { (cm) }\end{array}$ & $\begin{array}{l}\text { Chlorophyll } \\
\text { content } \\
(\mu \mathrm{g} / \mathrm{gm})\end{array}$ & $\begin{array}{l}\text { Spiklets } \\
(\mathrm{gm} / 100)\end{array}$ & $\begin{array}{l}\text { Grain Yield } \\
\text { Q/H }\end{array}$ \\
\hline Control & 66.33 & 9.23 & 14.82 & 256.37 & 26.70 \\
\hline P-suraksha ${ }^{\$}$ & 73.00 & 11.24 & 24.09 & 287.19 & 32.55 \\
\hline $\mathrm{PSB}^{\$}$ & 74.00 & 10.94 & 15.03 & 268.23 & 30.44 \\
\hline DFC31 & 74.33 & 13.06 & 19.97 & 319.07 & 34.45 \\
\hline PAID & 76.67 & 10.83 & 22.15 & 277.63 & 33.72 \\
\hline$A Z O^{\$}$ & 74.67 & 10.04 & 16.00 & 269.18 & 31.45 \\
\hline SCW1 & 77.67 & 14.25 & 26.83 & 334.00 & 40.25 \\
\hline $\mathrm{F}$ & 3.49 & 44.58 & 14.01 & 256.13 & 2.92 \\
\hline P-value* & 0.025 & $2.48 \times 10^{-08}$ & $3.33 \times 10^{-0 b}$ & $1.73 \times 10^{-13}$ & 0.046 \\
\hline
\end{tabular}

Each value represents the mean of three replicates; $*$ The difference in the mean values among the treatment groups are greater than would be expected by chance; there is a statistically significant difference as $\mathrm{P}$ value is $<0.05\left(\mathrm{~F}_{\text {crit }} 2.84\right)$

DFC 31 = P. putida; SCW1 = A. calcoaceticus; Azo $\$$ (Azotobacter); P-suraksha ${ }^{\$}(\mathrm{PGPR})$ and $\mathrm{PSB}^{\$}(\mathrm{Phosphate}$ solubilizing bacteria); PAID = P. aeruginosa ID 4365 (marine origin, NMU repository)

$\$$ Commercial formulation of International Panacea, Delhi 
Purified siderophore of Acinetobacter calcoaceticus at $500 \mu \mathrm{g} / \mathrm{mL}$ concentration inhibited growth of Aspergillus niger up to $30.00 \%$, A. flavus up to $10.71 \%$, Colletotrichum capsicum up to $21.57 \%$, and Fusarium oxysporum up to $15.12 \%$ inhibition was observed. These results suggest that both siderophore rich supernatant as well as pure siderophore has the inhibitory potential against phytopathogenic fungi.

Influence of this strain on wheat growth (Table 3) showed $25.2 \%$ increase in the rate of germination, $45.08 \%$ and $12.76 \%$ in the root length and dry weight, respectively. Subsequently, $2.71 \%$ and $24.29 \%$ increase in the shoot length and dry weight respectively were observed over control. Results indicate that Acinetobacter calcoaceticus has growth promotion as well as phytopathogen suppression activities.

In field application, the treatments effect was found significant in respect of shoot length, root length, chlorophyll content in leaves, weight of spiklets and grain yield during field experimentation. Seeds treated with SCW1 followed by DFC31 and PAID supported for maximum growth promotion of plants as depicted in Table 4. The grain yield was highest with $A$. calcoaceticus $(50.74 \%)$ followed by $P$. putida $(29.02 \%)$ and $P$. aeruginosa (26.29\%) over check without seed treatment. Commercial formulation viz. P-suraksha, PSB and $A Z O$ also significantly increased yield of grain by $21.91 \%, 14.0 \%$ and $17.79 \%$ respectively.

Use of siderophoregenic $A$. calcoaceticus improved crop growth and yield compared to other PGPR traits viz. $P$ solubilization and $N$ fixation under natural conditions indicates that siderophore production is an efficient parameter for preliminary selection of promising PGPR. Although siderophores are well known for contribution in plant growth promotion and biocontrol activity, other properties of strain also contribute to these feature positively. Considering this fact, further investigation in this direction revealed that like most other PGPRs, $A$. calcoaceticus has ability to synthesize IAA from tryptophan and solubilize tri-calcium phosphate. Previously, Huddedar et al., (2002) have described plasmid pUPI126 mediated indole 3 acetic acid (IAA) production in Acinetobacter strains from rhizosphere of wheat. Although, siderophore was dominant secondary metabolites in test organism, it was also capable of producing other metabolites such as IAA, phosphate solublizing organic acid in meager quantity.

Strains of Acinetobacter calcoaceticus have been previously isolated from rhizosphere (Sturz et al., 2001; Lappin et al., 1985). It is also observed that this strain lack of DNase and hemolytic activity (Table 1). This indicates that strain under study is distinct and different from siderophore producing clinical isolates of Acinetobacter sp. (Yamamoto et al., 1994). These results are promising for the development of siderophoregenic plant growth promoting Acinetobacter based bio-fertilizer and bio-fungicide. To our knowledge this is first report on A. calcoaceticus as an efficient PGPR. The large-scale application of $A$. calcoaceticus to wheat plants as bioinoculant would be attractive as it would substantially reduce the use of chemical fertilizers and pesticides, which often pollute the environment.

\section{ACKNOWLEDGEMENTS}

For this work financial support was received from University Grants Commission through SAP-DRS Program. Authors are indebted to Prof. K. B. Patil, ViceChancellor, NMU, Jalgaon, India, for encouragement and Dr. Yogesh Shouche, NCCS, Pune for kind help.

\section{REFERENCES}

Arnow, L. E. (1937). Colorimetric determination of the components of 3,4-dihydroxyphenylalanine- tyrosine mixtures. Journal of Biological Chemistry. 118, 531537.

Bano, N. and Musarrat, J. (2003). Characterization of a new Pseudomonas aeruginosa Strain $\mathrm{NJ}-15$ as a potential biocontrol agent. Current Microbiology 46, 324-328.

Bevivino, A., Tabacchioni, S., Chiarini, L., Carusi, M., Del Gallo, M. and Visca, P. (1994). Phenotypic comparison between rhizosphere and clinical isolates of Burkholderia cepacia. Microbiology 140, 1069-1077.

Budzikiewicz, H. (1993). Secondary metabolites from fluorescent Pseudomonads. FEMS Microbiology Reviews 204, 209-228.

Chincholkar, S. B., Chaudhari, B. L. and Rane, M. R. (2007a). Microbial Siderophores: State of art. In: Microbial Siderophores. Chincholkar, S. B. and Varma, A. (eds.) Springer Verlag, Germany, pp. 233-242.

Chincholkar, S. B., Chaudhari, B. L., Rane, M. R. and Sarode, P. D. (2007b). Fungal phytopathogen suppression using siderophoregenic bio-inoculants. In: Biological Control of Plant Diseases: Current Concepts. Chincholkar, S. B. and Mukerji, K.G. (eds). Haworth Press, USA, pp. 401-417

Csaky, T. (1948). On estimation of bound hydroxylamine in biological materials. Acta Chemica Scandinavica 2 , 450-454.

De Meyer, G., Capieau, K., Audenaert, K., Buchala, A., Metraux, J. P., and Hofte, M. (1999). Nanogram amounts of salicylic acid produced by the rhizobacterium Pseudomonas aeruginosa 7NSK2 activate the systemic acquired resistance pathway in bean. Molecular Plant-Microbe Interactions 12, 450458.

Glandorf, D. C. M., van der Sluis, I., Anderson, A.J., Bakker, P. A. H..M. and Schippers, B. (1994). Agglutination, adherence and root colonization by fluorescent pseudomonads. Applied and Environmental Microbiology 60, 1726-1733.

Hebber, K. P. and Lumsden, R. D. (1999). Biological control of seedling disease, In Biopesticides: Use and Delivery, Hall, F. R. and Menn, J. J. (eds.), Humana Press, Totowa, New Jersey pp. 103-116. 
Huddedar, S. B., Shete, A. M., Tilekar, J. N., Gore, S. D., Dhavale, D. D. and Chopade, B. A. (2002). Isolation, characterization and plasmid pUPI126 mediated indole 3 acetic acid (IAA) productions in Acinetobacter strains from rhizosphere of wheat. Applied Biochemistry and Biotechnology 102-103, 21-29.

Juni, E. (1984). Genus III. Acinetobacter Brisou et Pre'vot 1954, In Bergey's manual of systematic bacteriology, vol. 1., Krieg, N. R. and Holt, J. G. (eds.) The Williams \& Wilkins Co., Baltimore pp. 303-307.

Lankford, C. E. (1973). Bacterial assimilation of iron. Critical Reviews in Microbiology 2, 273-331.

Lappin, H. M., Greavers, M. P. and Slater, J. H. (1985). Degradation of herbicide mecoporop [2-(2-methyl-4chlorophenoxy) propionic acid] by synergistic microbial community. Applied and Environmental Microbiology 49, 429-433.

Meyer, J. M. and Abdallah, M. A. (1978). The Fluorescent pigments of Fluorescent pseudomonas: Biosynthesis, purification and physicochemical properties. Journal of General Microbiology 107, 319-328.

Payne, S. M. (1994). Detection, isolation and characterization of siderophores. Methods in Enzymology 235, 329-344.

Pidiyar, V. J., Jangid, K., Patole, M. S. and Shouche, Y. S. (2004). Studies on cultured and uncultured microbiota of wild Culex quinquefasciatus mosquito midgut based on 165 ribosomal RNA gene analysis. American Journal of Tropical Medicine and Hygiene 70, 597-603.

Pikovskaya, R. I. (1948). Mobilization of phosphorus in soil: in some microbial species. Mikorobiologia 17, 363-370.

Schwyn, B. and Neilands, J. B. (1987). Universal chemical assay for the detection and determination of siderophores. Analytical Biochemistry 160, 47-56.

Sharaf, E. F., Farrag, A. A., (2004). Induced resistance in tomato plants by IAA against Fusarium oxysporum lycopersici. Polish Journal of Microbiology 53, 111116.

Sharma, A., Johri, B. N., (2003). Growth promoting influence of siderophore-producing Pseudomonas strains GRP3A and PRS9 in maize, Zea mays L. under iron limiting conditions. Microbiology Research 158, 243-248.

Sturz, A. V., Matheson, B. G., Arsenault, W., Kimpinski, J. and Christie, B. R. (2001). Weeds as a source of plant growth promoting rhizobacteria in agricultural soils. Canadian Journal of Microbiology 47, 1013-1024.

Vansuyt, G., Robin, A., Briat, J. F., Curie, C. and Lemanceau, P. (2007). Iron acquisition from Fepyoverdine by Arabidopsis thaliana. Molecular PlantMicrobe Interactions 20, 441-447.

Voisard, C., Keel, C., Haas, D. and Défago, G. (1989). Cyanide production by Pseudomonas fluorescens helps suppress black root rot of tobacco under gnotobiotic conditions. European Molecular Biology Organization Journal 8, 351-358.

Yamamoto, S., Okujo, N. and Sakakibara, Y. (1994). Isolation and structure elucidation of acinetobactin a novel siderophore from Acinetobacter baumannii. Archives of Microbiology 162, 249-254. 